\title{
Raleio de cachos sobre o potencial enológico da uva 'Cabernet Franc' em duas safras
}

\author{
A survey of clusters thinning in the 'Cabernet Franc' winemaking potential in two seasons
}

\author{
José Luiz Marcon Filho $^{I^{*}}$ Joseane De Souza Hipólito $^{\mathrm{I}}$ Tiago Afonso De Macedo \\ Aike Anneliese Kretzschmar ${ }^{I}$ Leo Rufato ${ }^{I}$
}

\section{RESUMO}

O presente trabalho teve como objetivo avaliar a maturação tecnológica e fenólica das uvas na variedade 'Cabernet Franc', submetida a diferentes niveis de raleio de cachos, de modo a estabelecer critérios que contribuam para definir o manejo mais apropriado para a obtenção de uvas destinadas à elaboração de vinhos finos, em regiões acima de $900 m$ de altitude. Os ensaios foram conduzidos durante as safras 2009/10 e 2010/11 em um vinhedo comercial a 1,230m de altitude, localizado no municipio de São Joaquim, SC, coordenadas $28^{\circ} 17^{\prime} 39^{\prime}$ 'S e 49 55' 56" W. Foi utilizada a variedade 'Cabernet Franc', enxertada sobre 'Paulsen 1103', conduzida em espaldeira, com espaçamento de 3,0m $\times 1,2 \mathrm{~m}$ e cobertura anti-granizo. Os níveis de raleio de cachos, ajustados na virada de cor "véraison", corresponderam à produção máxima, com reduções percentuais em sua produtividade em $25 \%$, 50\% e $75 \%$. Observou-se que, em região de altitude, a prática de raleio de cachos modifica as características químicas da uva 'Cabernet Franc', aumentando o $\mathrm{pH}$, reduzindo o teor de SS do mosto e polifenóis da casca. A realização do raleio de cachos, além de reduzir a produção por área, não teve um efeito compensatório na qualidade do mosto, além de não ter sido observado equilibrio vegetativo/produtivo das plantas. A redução da carga através da prática do raleio de cachos não gerou os beneficios esperados para a cv. 'Cabernet Franc', cultivada em região de altitude nas duas safras avaliadas.

Palavras-chave: Vitis vinifera L., manejo da planta, maturação da uva, polifenóis totais, viticultura de altitude.

\section{ABSTRACT}

This study aims to evaluate the ripening of 'Cabernet Franc's' grape berries submitted to different levels of clusters thinning in order to establish criteria that will help to define the most appropriate management for winemaking in regions above $900 \mathrm{~m}$. The experiment was conducted during the growing seasons of 2009/10 and 2010/11 in a commercial vineyard (28 17'39",
S e 49 55' 56" W, 1,230m), located in São Joaquim, SC. Plants are grafted on Paulsen 1103 and conducted in vertical shooting positioning trellis, spacing $3.0 \times 1.2 \mathrm{~m}$ and covered with hail protection net. Levels of clusters thinning, set at "véraison", corresponded to maximum production, and percentage reductions in productivity by $25 \%, 50 \%$ and $75 \%$. In the region of altitude, the practice of clusters thinning modifies the chemical composition of 'Cabernet Franc's' grape berries. Besides reducing the production per area, this practice does not have a compensatory effect of lower productivity in the quality of wine and equilibrium vegetative/ productive plants as well. Reducing production through clusters thinning did not reach the expected benefits for $\mathrm{cv}$. 'Cabernet Franc'in this survey.

Key words: Vitis vinifera $L .$, management, ripening, total polyphenols, altitude wines.

\section{INTRODUÇÃO}

A produção de uvas em região de altitude no estado de Santa Catarina vem ganhando destaque no cenário vitivinícola nacional. O município de São Joaquim, na Serra Catarinense, devido às suas condições climáticas particulares, favorece o cultivo de variedades de uvas Vitis vinifera L., as quais atingem índices de maturação que permitem fornecer matéria prima para elaboração de vinhos diferenciados por sua intensa coloração, aroma e equilíbrio gustativo (GRIS et al., 2010).

Aaltitude elevada dessa região, 1.200 a 1.400m, proporciona maior amplitude térmica, com temperaturas noturnas amenas. Essas temperaturas influenciam no metabolismo da videira, retardam o amadurecimento dos

\footnotetext{
IDepartamento de Agronomia, Centro de Ciências Agroveterinárias (CAV), Universidade do Estado de Santa Catarina (UDESC), 88520-000, Lages, SC, Brasil. E-mail: marconfilho j1@yahoo.com.br. "Autor para correspondência. 
frutos, reduzem o crescimento das plantas e permitem uma maturação mais completa (ROSIER, 2006).

A uva 'Cabernet Franc' é uma variedade de $\boldsymbol{V}$. vinifera $\mathrm{L}$. de antiga existência na França. No Brasil, seu cultivo somente se expandiu a partir dos anos 70, adaptando-se bem aos solos do estado do Rio Grande do Sul (RIZZON \& MIELE, 2001), entretanto tem-se observado grande potencial dessa variedade na produção de vinhos tintos finos em regiões do planalto catarinense.

A variedade, o clima, o solo e o sistema de produção influenciam no vigor da videira, determinando as características do dossel, microclima, sanidade e maturação da uva, fatores que determinam a qualidade do vinho (REYNOLDS \& HEUVEL, 2009). Conhecer as características do vinhedo que favoreçam a qualidade do vinho é fundamental para propor técnicas de manejo adequadas, que permitam alcançar condições ótimas no momento da vindima.

$\mathrm{Na}$ videira, assim como na maioria das espécies frutíferas, o balanço entre a carga de frutas (dreno) e a área foliar adequadamente iluminada (fonte) influenciam na quantidade e na qualidade da produção. $\mathrm{O}$ equilíbrio entre esses dois parâmetros é determinante para a composição e a maturação das bagas. Pode-se manter o equilíbrio na relação fonte/ dreno através de técnicas de manejo do vinhedo, como podas, remoção de folhas ou raleio de cachos (REYNOLDS \& WARDLE, 1989; SILVA et al., 2009; FREDES et al., 2010).

O raleio de cachos permite o controle da produção, particularmente durante a fase reprodutiva, no entanto, pode afetar o desempenho vegetativo e produtivo da planta (RUFATO \& BRIGHENTI, 2010). Pesquisas demonstraram que a realização do raleio de cachos afeta as características físico-químicas deles (FANZONE et al., 2011). Estas características podem ter influência direta ou indireta na qualidade final da uva. Alguns trabalhos descrevem a influência do raleio de cachos na composição química do mosto (DAMI et al., 2006; SILVA et al., 2008; MOTA et al., 2010). O raleio de cachos busca melhorar a qualidade da uva, pois altera a relação folha/fruto, e pode adequar o aporte de carboidratos aos cachos, além de modificar o microclima do dossel, o que favorece o desenvolvimento e a maturação das bagas (ALMANZA-MERCHÁN et al., 2011).

Devido à falta de informações referentes à variedade 'Cabernet Franc' em condições de altitude no estado de Santa Catarina, o objetivo deste trabalho foi avaliar o efeito de diferentes intensidades de raleio de cachos na maturação tecnológica dos frutos e no seu potencial enológico.

\section{MATERIAL E MÉTODOS}

O experimento foi conduzido durante as safras 2009/10 e 2010/11, em um talhão do vinhedo, de propriedade da Villa Francioni Agronegócios S/A, coordenadas $28^{\circ} 17^{\prime} 39^{\prime \prime} \mathrm{S}$ e $49^{\circ} 55^{\prime} 56^{\prime}$ ' O, a $1.230 \mathrm{~m}$ de altitude, localizado no município de São Joaquim, Santa Catarina. O clima da região é classificado como 'Frio, Noites Frias e Úmido', Índice Heliotérmico de 1,714 , precipitação pluvial média anual de $1,621 \mathrm{~mm}$ e a umidade relativa do ar média anual de $80 \%$ (TONIETTO \& CARBONNAU, 2004).

Foi utilizado um vinhedo de 'Cabernet Franc', enxertada sobre 'Paulsen 1103', de seis anos de idade, na safra 2009/10, e sete anos, em 2010/11, com plantas uniformes em vigor e desenvolvimento, sendo utilizadas nas duas safras. $\mathrm{O}$ vinhedo se caracteriza por apresentar plantas espaçadas de 3,0 x 1,2m, em filas dispostas no sentido N-S, conduzidas em espaldeira, podadas em cordão esporonado duplo, a 1,2m de altura e cobertas com clarite de proteção anti-granizo.

Os tratamentos corresponderam à produção máxima (Testemunha) e reduções percentuais em produtividade, ajustadas quando $50 \%$ das bagas encontravam-se na virada de cor "véraison", correspondendo ao dia 10 de fevereiro de 2010 e 2011. No raleio, retirou-se primeiramente os cachos mal posicionados e pequenos e, caso a quantidade remanescente não correspondesse ao nível de raleio desejado, eram retirados os cachos sobressalentes, eliminando os cachos duplos nos sarmentos. Buscouse sempre deixar um cacho por sarmento para o seu pleno desenvolvimento.

Calculou-se a intensidade de raleio com base no número médio de cachos por planta $(n=50)$. Para a safra 2009/10, o número médio de 17 cachos por planta correspondeu ao tratamento: 1) Testemunha (sem raleio), 2) Raleio de 25\%, com 13 cachos; 3) Raleio de 50\%, com 9 cachos; 4) Raleio de 75\%, com 4 cachos por planta. O mesmo procedimento foi adotado na safra 2010/11, porém considerando a média de 22 cachos por planta, que consistiram nos tratamentos: 1) Sem raleio (22 cachos); 2) Raleio de 25\% (17 cachos); 3) Raleio de 50\% (11 cachos); e 4) Raleio de $75 \%$ (6 cachos). O delineamento utilizado foi em blocos casualizados com quatro repetições e 10 plantas por parcela.

Acolheita foi realizada seguindo os padrões da vinícola, quando alcançada a média de $20^{\circ}$ Brix na testemunha, em 06 de abril de 2010 e 07 de abril de 2011. No momento da colheita, foram coletadas 150 bagas por parcela, segundo metodologia proposta por RIZZON \& MIELLE (2001), para a determinação 
das características físico-químicas da uva. A partir do mosto das bagas, foi determinado o teor de sólidos solúveis (SS) utilizando um refratômetro digital para açúcar, modelo ITREFD-45, sendo os resultados expressos em ${ }^{\circ}$ Brix. A acidez total (AT) foi obtida através da titulação do mosto com solução alcalina padronizada de hidróxido de sódio $0,1 \mathrm{~N}$, utilizando como indicador o azul de bromotimol, sendo os resultados expressos em meq $\mathrm{L}^{-1}$. $\mathrm{O}$ potencial hidrogeniônico $(\mathrm{pH})$ foi registrado por meio de um potenciômetro marca Impac, após calibração em soluções tampões conhecidas de pH 4,0 e 7,0.

$\mathrm{Na}$ safra 2011, também se avaliou a concentração de polifenóis totais. Para a obtenção das soluções-extrato, foram separadas manualmente $100 \mathrm{~g}$ de cascas a partir das amostras de bagas, às quais foram adicionados $40 \mathrm{~mL}$ de solução hidroalcoolica de metanol $50 \% \mathrm{v} \mathrm{v}^{-1}$, e mantidas a $30^{\circ} \mathrm{C}\left( \pm 0,5^{\circ} \mathrm{C}\right)$ por 24 horas. Após este período, o extrato obtido foi reservado e adicionou-se novamente $40 \mathrm{~mL}$ da solução extratora de metanol às cascas, que, em seguida, foram colocadas em BOD, para a extração a $0^{\circ} \mathrm{C}\left( \pm 0,5^{\circ} \mathrm{C}\right)$ por mais 24 horas. As soluções da primeira e segunda extração foram homogeneizadas e filtradas ao final do processo.

A concentração de polifenóis totais (PT) na casca foi determinada pelo método de espectrofotometria, descrito por SINGLETON \& ROSSI (1965), utilizando o reagente Folin-Ciocalteu e o ácido gálico como padrão. A curva de calibração foi construída utilizando-se concentrações de 100 , 200, 300, 400, 500 e 600 $\mathrm{mg} \mathrm{L}^{-1}$ de ácido gálico. Os resultados foram expressos em $\mathrm{mg} \mathrm{L}^{-1}$ de polifenóis totais expressos em equivalentes de ácido gálico.

A mensuração do equilíbrio entre o crescimento vegetativo e produtivo foi realizada através do índice de Ravaz (IR), que é o quociente entre a massa média dos cachos, produzida por uma determinada planta em $\mathrm{kg}$, e a massa média dos sarmentos em $\mathrm{kg}$, produzidos pela mesma planta, mensurado na época da poda de frutificação com a média de 4 plantas por parcela.

Para cálculo da produção por planta, utilizou-se a massa média de 20 cachos por tratamento, colhidos aleatoriamente dentro de cada parcela na colheita, multiplicada pelo número de cachos por planta, deixados no momento do raleio em cada tratamento. A produção estimada foi de 2,3; 1,9; 1,5 e $0,6 \mathrm{~kg}$ planta $^{-1}$ para a safra $2009 / 10$ e 4,$1 ; 3,1 ; 2,1$ e $1,1 \mathrm{~kg}$ planta $^{-1}$ para a safra 2010/11 nas intensidades de $0,25,50$ e $75 \%$ de raleio, respectivamente.

Os resultados foram submetidos à análise de variância, em esquema fatorial $2 \times 4$, considerando as safras como fator. Os efeitos dos tratamentos foram avaliados pelo teste de Tukey a 5\% de probabilidade de erro e regressão polinomial.

\section{RESULTADOS E DISCUSSÃO}

A relação entre a produção de frutos por planta $(\mathrm{kg})$ e a massa do material podado $(\mathrm{kg})$, obtido pelo Índice de Ravaz, teve uma variação entre 3,10 e 0,76 na safra 2010 e 3,33 e 0,87 na safra 2011 (Tabela 1), observando uma tendência linear negativa para essa variável (Figura 1A). Vários estudos têm demonstrado que valores do Índice de Ravaz entre 4 e 7 são bons indicativos de videiras equilibradas, capazes de produzir frutas de qualidade (SILVA et al., 2009; FREDES et al., 2010). Índices maiores que 7 indicam excesso de produção de frutos, e os menores que 4 demonstram vigor excessivo da planta (HOWELL, 2001). Os resultados observados se encontram abaixo de 4 , sugerindo que há vigor excessivo das plantas em todos os tratamentos, mesmo com a manutenção de toda a carga da planta, que foi de $6,4 \mathrm{tha}^{-1}$ em $2010 \mathrm{e}$ 11,3t ha- em 2011, na testemunha.

Esse efeito poderia ser minimizado realizando o desponte dos ramos na fase vegetativa ou aumentando a carga de frutos, pois, segundo GONZÁLES-NEVES \& FERRER (2008), toda e qualquer técnica de manejo do vinhedo que modifique as relações entre fonte e dreno reflete diretamente na qualidade da uva.

MOTA et al. (2010), avaliando o efeito do raleio de cachos e do desponte de ramos em 'Cabernet Sauvignon' e 'Merlot', observaram grande variação no Índice de Ravaz entre tratamentos, variando de 3,8 a 10. Os autores relatam ainda que, apesar da ampla variação observada, não houve relação clara entre esse índice e a composição das frutas.

Houve efeito significativo da intensidade de raleio de cachos nos parâmetros que definem as características de maturação tecnológica dos frutos, como SS, AT, $\mathrm{pH}$ e polifenóis totais das bagas. Os valores desses parâmetros, obtidos nas diferentes intensidades de raleio, estão adequados para elaboração de vinhos (Tabela 1). GRIS et al. (2010) e BRIGHENTI et al. (2013) também encontraram valores similares quando estudaram o comportamento da variedade 'Cabernet Franc' em São Joaquim, SC.

Nas diferentes intensidades de raleio, a redução dos cachos diminuiu o SS no mosto das uvas da cv 'Cabernet Franc' em relação à testemunha para a safra 2009/10 e não se observou diferença entre os tratamentos para a safra 2010/11 (Tabela 1). Verificou-se uma diminuição de $1,9^{\circ}$ Brix da maior para a menor produção na safra 2009/10, sendo este 
Tabela 1 - Índice de Ravaz (IR); Teor de sólidos solúveis ( ${ }^{\circ}$ Brix) (SS), Acidez total (meq L ${ }^{-1}$ ) (AT) e Potencial hidrogeniônico (pH) do mosto na safra 2009/10 e 2010/11; Polifenóis totais da casca (D.O.760) (mg L $\mathrm{m}^{-1}$ equivalente de ácido gálico) na safra 2010/11 (PT), realizados no momento da vindima da cv. 'Cabernet Franc', segundo os níveis de raleio de cachos, ajustados na virada de cor “véraison”, em $0 \%, 25 \%, 50 \%$ e $75 \%$. São Joaquim $/ 2012$.

\begin{tabular}{|c|c|c|c|c|c|c|}
\hline & \multirow{2}{*}{ Safra } & \multicolumn{4}{|c|}{ - } & \multirow{2}{*}{ média } \\
\hline & & 0 & 25 & 50 & 75 & \\
\hline \multirow{3}{*}{ IR } & 2010 & $3,10 \pm 0,55^{\mathrm{Aa}}$ & $2,61 \pm 0,20^{\mathrm{AB} a}$ & $2,07 \pm 0,65^{\mathrm{B} \mathrm{a}}$ & $0,76 \pm 0,16^{\mathrm{Ca}}$ & $2,14 \pm 0,98^{\mathrm{a}}$ \\
\hline & 2011 & $3,33 \pm 0,41^{\mathrm{Aa}}$ & $2,63 \pm 0,55^{\mathrm{A}}$ a & $1,46 \pm 0.35^{\mathrm{B} \mathrm{b}}$ & $0,87 \pm 0,23^{\mathrm{Ba}}$ & $2,07 \pm 1,06^{\mathrm{a}}$ \\
\hline & Média & $3,21 \pm 0,47^{\mathrm{A}}$ & $2,62 \pm 0,38^{\mathrm{B}}$ & $1,77 \pm 0,58^{\mathrm{C}}$ & $0,82 \pm 0,19^{\mathrm{D}}$ & - \\
\hline \multirow{3}{*}{$\mathrm{SS}\left({ }^{\circ} \mathrm{Brix}\right)$} & 2010 & $18,22 \pm 0,60^{\mathrm{Ab}}$ & $15,90 \pm 0,73^{\mathrm{B} \mathrm{b}}$ & $16,58 \pm 0,82^{\mathrm{B} \mathrm{b}}$ & $16,30 \pm 1,10^{\mathrm{B} \mathrm{b}}$ & $16,75 \pm 1,18^{\mathrm{b}}$ \\
\hline & 2011 & $21,30 \pm 0,33^{\mathrm{Aa}}$ & $21,17 \pm 0,04^{\mathrm{Aa}}$ & $21,17 \pm 0,24^{\mathrm{Aa}}$ & $20,67 \pm 0,25^{\mathrm{Aa}}$ & $21,07 \pm 0,33^{\mathrm{a}}$ \\
\hline & Média & $19,76 \pm 1,70^{\mathrm{A}}$ & $18,54 \pm 2,85^{\mathrm{B}}$ & $18,87 \pm 2,52^{\mathrm{B}}$ & $18,48 \pm 2,45^{\mathrm{B}}$ & - \\
\hline \multirow{3}{*}{$\mathrm{pH}$} & 2010 & $3,35 \pm 0,02^{\mathrm{Ca}}$ & $3,43 \pm 0,09^{\mathrm{BC} \mathrm{a}}$ & $3,50 \pm 0,06^{\mathrm{AB} \mathrm{a}}$ & $3,55 \pm 0,05^{\mathrm{Aa}}$ & $3,46 \pm 0,09^{\mathrm{a}}$ \\
\hline & 2011 & $3,22 \pm 0,01^{\mathrm{Ab}}$ & $3,25 \pm 0,00^{\mathrm{A}} \quad \mathrm{b}$ & $3,21 \pm 0,03^{\mathrm{A}} \mathrm{b}$ & $3,24 \pm 0,02^{\mathrm{Ab}}$ & $3,23 \pm 0,02^{\mathrm{b}}$ \\
\hline & Média & $3,29 \pm 0.07^{\mathrm{B}}$ & $3,34 \pm 0,11^{\mathrm{AB}}$ & $3,36 \pm 0,16^{\mathrm{A}}$ & $3,40 \pm 0,17^{\mathrm{A}}$ & - \\
\hline \multirow{3}{*}{ AT $\left(\right.$ meq L L $\left.^{-1}\right)$} & 2010 & $109,00 \pm 8,87^{\mathrm{A} \mathrm{a}}$ & $81,30 \pm 12,36^{\mathrm{B} \mathrm{b}}$ & $75,00 \pm 7,57^{\mathrm{B} \mathrm{b}}$ & $74,70 \pm 3,77^{\mathrm{B} \mathrm{b}}$ & $85,00 \pm 16,52^{b}$ \\
\hline & 2011 & $99,00 \pm 1,47^{\mathrm{Aa}}$ & $97,20 \pm 8,82^{\mathrm{Aa}}$ & $102,60 \pm 4,41^{\mathrm{Aa}}$ & $89,10 \pm 0,73^{\mathrm{Aa}}$ & $97,00 \pm 6,79^{a}$ \\
\hline & Média & $104,00 \pm 8,87^{\mathrm{A}}$ & $89,30 \pm 13,07^{\mathrm{B}}$ & $88,80 \pm 15,83^{\mathrm{B}}$ & $81,90 \pm 8,11^{\mathrm{B}}$ & - \\
\hline PT $\left(\mathrm{mg} \mathrm{L}^{-1}\right)$ & 2011 & $4030,50 \pm 10,21^{\mathrm{A}}$ & $4005,75 \pm 213,31^{\mathrm{A}}$ & $3643,30 \pm 12,04^{\mathrm{B}}$ & $3333,00 \pm 143,30^{C}$ & - \\
\hline
\end{tabular}

${ }^{a}$ Valores com sobrescritos minúsculos distintos em uma mesma coluna e maiúsculos em uma mesma linha são estatisticamente diferentes, de acordo com ANOVA $(\mathrm{P}<0,05)$ e pelo teste de Tukey $(\mathrm{P}<0,05)$, respectivamente.

valor relevante para o potencial de produção de álcool. $\mathrm{Na}$ safra 2009/10, o teor de sólidos solúveis, para todos os tratamentos, permaneceu abaixo de $20^{\circ}$ Brix, demonstrando que ainda haveria potencial de aumento deste parâmetro, caso os frutos permanecessem na planta, porém as condições climáticas e a elevada incidência de doenças levaram à realização da colheita sem atingir o máximo teor de açúcar nesta safra. Além disso, a maior precipitação desse ano (dados não reportados) também influenciou no menor teor de SS na colheita, devido à diluição do mosto na baga.

Considerando a média dos dois anos, observou-se tendência de redução do teor de sólidos solúveis em até $1,3^{\circ}$ Brix, com a redução da produção (Figura 1B). Na prática, esse valor pode afetar consideravelmente a característica do vinho, pois o açúcar é essencial para o crescimento e desenvolvimento das leveduras, as quais, durante a fermentação, metabolizam, principalmente em etanol, e também os açúcares podem ser transformados em alcoois superiores, ácidos graxos, ésteres e aldeídos, os quais proporcionam para os diferentes vinhos muitos dos seus aromas (FREGONI, 1998; JACKSON, 2008).
Observa-se que, nas plantas sem raleio de cacho, ocorreu maior acúmulo de ácidos na safra 2009/10 e não se observou diferença entre os níveis de raleio para a safra 2010/11 (Tabela 1), observandose tendência linear negativa com o aumento da intensidade de raleio na média das duas safras (Figura 1C). O comportamento diferenciado entre as safras pode ser atribuído às condições desfavoráveis à maturação das uvas na safra 2009/10, como a precipitação excessiva (dados não reportados).

$\mathrm{O}$ pH do mosto aumentou linearmente com a maior intensidade de raleio, considerando a média das duas safras (Figura 1D). Para a safra 2009/10, nas plantas sem raleio, observou-se o menor valor de pH $(3,35)$, diferindo dos tratamentos de 50 e $75 \%$ de intensidade de raleio. No entanto, não se observou diferença no $\mathrm{pH}$ do mosto entre os níveis de raleio de cacho para a safra 2010/11 (Tabela 1).

A sensação ácida de frescor em vinhos tintos está diretamente relacionada ao $\mathrm{pH}$ e à acidez total. A recomendação de um valor ideal de $\mathrm{pH}$ não é precisa. No entanto, para vinhos tintos, o $\mathrm{pH}$ entre 3,3 e 3,6 garante uma melhor estabilidade microbiológica 


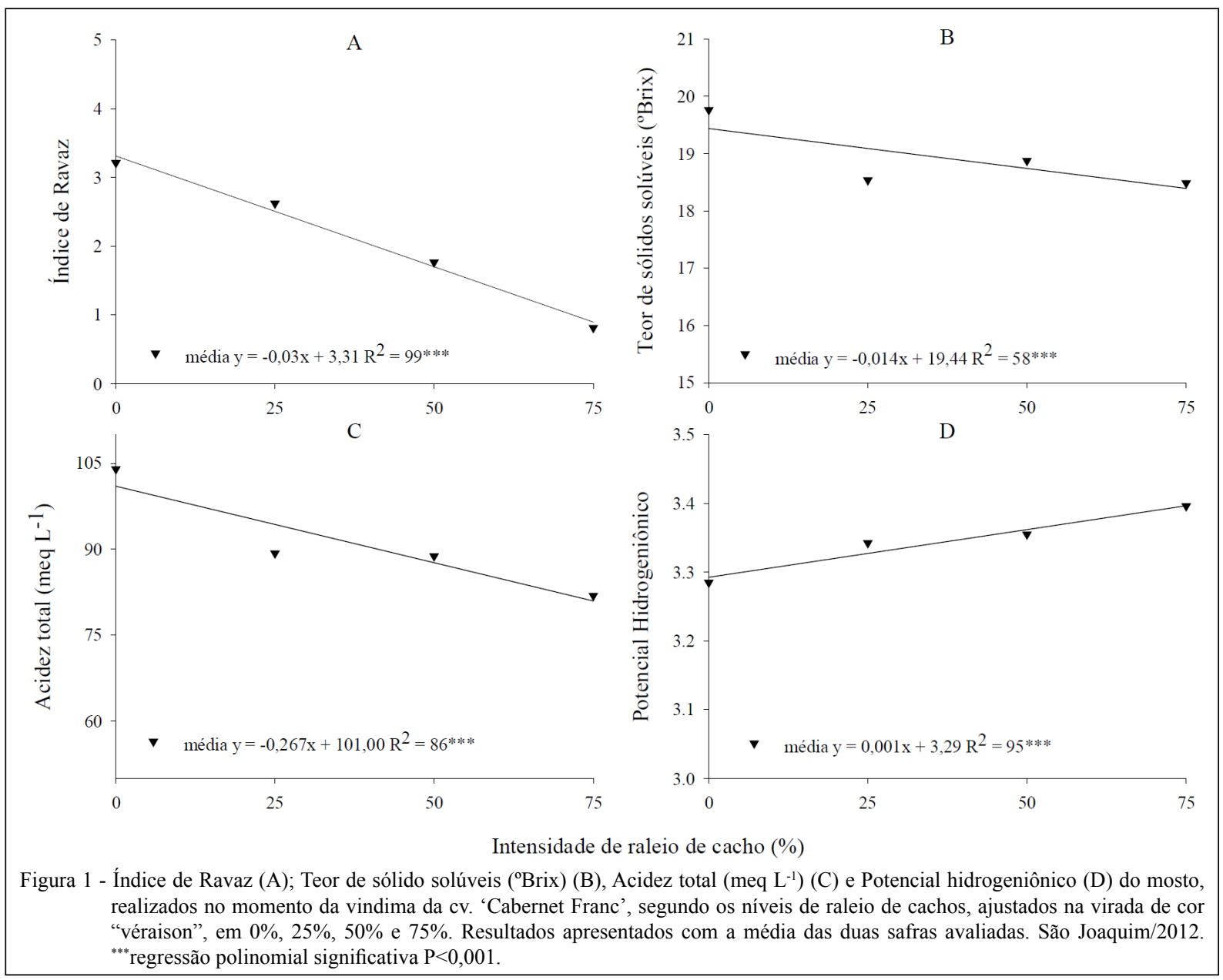

e físico-química (JACKSON, 2008). Observa-se, em todos os tratamentos, que os valores de $\mathrm{pH}$ obtidos estão dentro da variação sugerida, porém, para o mosto, valores mais baixos são preferidos, devido ao aumento do pH durante e após a fermentação.

Para a safra 2010/11, observou-se diferença entres os tratamentos para o teor de polifenóis na casca, ocorrendo uma redução na concentração de polifenois, conforme a redução da carga da planta (Tabela 1). O teor de compostos fenólicos na uva é influenciado por vários fatores, como a cultivar, a safra, o clima, o grau de maturação da uva, o status hídrico, a nutrição mineral, a época de colheita e a sanidade da uva (LEE \& JAWORSKI, 1987; REYNOLDS, 2010). Esta redução no teor de polifenóis pode ser explicada pelo aumento do vigor, conforme a maior intensidade de raleio, verificado através do Índice de Ravaz.

A região do planalto sul catarinense apresenta condições de solo e clima diferenciadas, proporcionando um excessivo crescimento vegetativo
(BORGHEZAN et al., 2011; ZALAMENA et al., 2013). Quando o ramo é vigoroso, resulta em maior atração dos carboidratos, principais precursores do polifenóis, em direção ao ápice vegetativo, enquanto o cacho permanece com pouco aporte de substâncias nutritivas, e seu desenvolvimento completo ou sua maturação ficam prejudicados (FREGONI, 1998; BRUNETTO et al., 2008).

Quando se avalia a qualidade da uva destinada à elaboração de vinhos, os principais compostos avaliados são açúcares, ácidos e polifenóis. Sendo assim, com base nas condições em que foi realizado o experimento e nos resultados obtidos, o $\mathrm{pH}$, o teor de açúcar e os polifenóis foram afetados de forma negativa. Da mesma maneira, em outros trabalhos realizados na região em estudo, observou-se comportamento similar quando se reduziu drasticamente a carga (SILVA et al., 2008; SILVA et al., 2009).

Dessa forma os resultados obtidos neste trabalho demonstram que o raleio não tem gerado 
os benefícios esperados ao viticultor, tendo em vista a redução da produção sem um aumento significativo na qualidade da uva para a produção de vinhos finos de alta qualidade. Deve-se destacar também que os resultados obtidos são apenas de duas safras, e refletem uma tendência, de forma que será necessária a continuidade desta investigação por um período maior de tempo para permitir segurança na recomendação do raleio de cachos em vinhedos de altitude para esta cultivar.

O raleio de cachos é uma prática que deve ser realizada com cautela, e não deve ser considerado como uma prática corrente na vitivinicultura, pois seu sucesso depende da finalidade a que se propõe. Deve-se analisar o ambiente, a planta e o objetivo da produção, para assim definir se é necessária a realização do raleio, pois, como se verificou neste e em outros trabalhos, a resposta ao raleio é muito dependente da variedade e das condições climáticas do ano agrícola.

\section{CONCLUSÃO}

Para as condições da região serrana de Santa Catarina, nos anos avaliados, a redução excessiva da carga na cv. 'Cabernet Franc' influencia negativamente no potencial enológico do mosto.

A realização do raleio de cachos na cv. 'Cabernet Franc' nas condições do ensaio, reduz a produção por área, sem efeito compensatório à menor produtividade na qualidade do mosto.

\section{REFERÊNCIAS}

ALMANZA-MERCHÁN, P.J. et al. Effects of leaf removal and cluster thinning on yield and quality of grapes (Vitis vinifera $\mathrm{L}$., Riesling $\times$ Silvaner) in Corrales, Boyaca (Colombia). Agronomía Colombiana, Bogotá, v.29, n.1, p.35-42, 2011. Disponível em: $<$ http://www.scielo.org.co/pdf/agc/v29n1/v29n1a05.pdf>. Acesso em: 18 nov. 2013

BORGHEZAN, M. et al. Comportamento vegetativo e produtivo da videira e composição da uva em São Joaquim, Santa Catarina. Pesquisa Agropecuária Brasileira, Brasília, v.46, n.4, p.398-405, 2011. Disponível em: <http://ref.scielo.org/6fyrwr >. Acesso em: 19 maio 2014. doi: 10.1590/S0100-204X2011000400009.

BRIGHENTI, A.F. et al. Caracterização fenológica e exigência térmica de diferentes variedades de uvas viníferas em São Joaquim, Santa Catarina - Brasil. Ciência Rural, Santa Maria, v.43, n.7, p.1162-1167, 2013. Disponível em: <http://www.scielo.br/pdf/cr/ v43n7/a18813cr2012-0848.pdf > . Acesso em: 30 maio 2015. doi: 10.1590/S0103-84782013005000082.

BRUNETTO, G. et al. Produção, composição da uva e teores de nitrogênio na folha e no pecíolo em videiras submetidas à adubação nitrogenada. Ciência Rural, Santa Maria, v.38, n.9, p.2622-2625, 2008. Disponível em: $<$ http://ref.scielo.org/fjv4mh $>$. Acesso em: 19 maio 2014. doi: 10.1590/S0103-84782008005000026.
DAMI, I. et al. A Five-year study on the effect of cluster thinning on yield and fruit composition of 'Chambourcin' grapevines. HortScience, Alexandria, v.41, n.3, p.586-588, 2006. Disponível em: $<$ http://hortsci.ashspublications.org/>. Acesso em: 18 nov. 2013.

FANZONE, M. et al. Phenolic composition of 'Malbec' grape skins and seeds from Valle de Uco (Mendoza, Argentina) during ripening. Effect of cluster thinning. Journal of Agricultural and Food Chemistry, Washington, v.59, p.6120-6136, 2011. Disponível em: <http://pubs.acs.org/doi/pdf/10.1021/jf200073k>. Acesso em: 18 nov. 2013. doi: 10.1021/jf200073k

FREDES, C. et al. Vine balance: a study case in 'Carménère' grapevines. Ciencia e Investigación Agraria, Santiago, v.37, n.1, p.143-150, 2010. Disponível em: <http://www.scielo.cl/pdf/ciagr/ v37n1/art14.pdf $>$. Acesso em: 18 nov. 2013. doi: 10.4067/S071816202010000100014

FREGONI, M. Viticoltura di qualitá. Verona: Edizione I’Informatore Agrário, 1998. 707p.

GONZÁLEZ-NEVES, G.; FERRER, M. Efectos del sistema de conducción y del raleo de racimos en la composición de uvas 'Merlot'. Agrociencia, Montevideo, v.12, n.2, p.10-18, 2008. Disponível em: $<\mathrm{http} / / / \mathrm{www}$.fagro.edu.uy/ agrociencia/index. php/directorio/article/view/161/103>. Acesso em: 18 nov. 2013.

GRIS, E.F. et al. Phenology and ripening of Vitis vinifera L. grape varieties in São Joaquim, southern Brazil: a new South American wine growing region. Ciencia e Investigación Agraria, Santiago, v.37, n.2, p.61-75, 2010. Disponível em: <http://www.scielo. cl/pdf/ciagr/v37n2/art07.pdf $>$. Acesso em: 18 nov. 2013. doi: 10.4067/S0718-16202010000200007.

HOWELL, G.S. Sustainable grape productivity and the growthyield relationship: a review. American Journal of Enology and Viticulture, Davis, v.52, n.3, p.165-174, 2001. Disponível em: $<\mathrm{http}: / / \mathrm{www}$.ajevonline.org/content $/ 52 / 3 / 165$.full.pdf $>$. Acesso em: 1 fev. 2015

JACKSON, R.S. Wine science: principles and applications. Canada: ELSEVIER, 2008. 751p.

MOTA, R.V. et al. Biochemical and agronomical responses of grapevines to alteration of source-sink ratio by cluster thinning and shoot trimming. Bragantia, Campinas, v.69, n.1, p.1725, 2010. Disponível em: <http://www.scielo.br/pdf/brag/ v69n1/04.pdf>. Acesso em: 18 nov. 2013. doi: 10.1590/S000687052010000100004 .

LEE, C.Y.; JAWORSKI, A. Phenolic compounds in white grapes grown in New York. American Journal of Enology and Viticulture, Davis, v.38, n.4, p.277-281, 1987. Disponível em: $<\mathrm{http}: / /$ www.ajevonline.org/content/38/4/277.short $>$. Acesso em: 05 fev. 2015.

REYNOLDS, A.G; HEUVEL, J.E.V. Influence of grapevine training systems on vine growthand fruit composition: a review. American Journal of Enology and Viticulture, Davis, n.60, p.251-268, 2009. Disponível em: <http://ajevonline.org/ content/60/3/251.full.pdf>. Acesso em: 18 nov. 2013.

REYNOLDS, A.G.; WARDLE, D.A. Impact of various canopy manipulation techniques on growth, yield, fruit composition, and wine quality of gewürztraminer. American Journal of Enology and Viticulture, Davis, 
n.40, p.121-129, 1989. Disponível em: <http://ajevonline. org/content/40/2/121.full.pdf $>$. Acesso em: 18 nov. 2013.

REYNOLDS, A.G. Managing wine quality: viticulture and wine quality. EUA: Woodhead Publishing, 2010. V.1. 606p.

RIZZON, L.A.; MIELE, A. Avaliação da cv. 'Cabernet Franc' para elaboração de vinho tinto. Ciência e Tecnologia de Alimentos, Campinas, v.21, n.2, p.249-255, 2001. Disponível em: <http:// www.scielo.br/pdf/cta/v21n2/7475.pdf $>$. Acesso em: 18 nov. 2013. doi: 10.1590/S0101-20612001000200022.

ROSIER, J.P. Vinhos de altitude: características e potencial na produção de vinhos finos brasileiros. Informe Agropecuário, Belo Horizonte, v.27, n.234, p.105-110, 2006

RUFATO, L.; BRIGHENTI, A.F. Produtividade e qualidade do vinho. Agropecuária Catarinense, Florianópolis, v.23, n.2, p.37-41, 2010.

SILVA, L.C. et al. Níveis de produção em vinhedos de altitude da cv. 'Malbec' e seus efeitos sobre os compostos fenólicos. Revista Brasileira de Fruticultura, Jaboticabal, v.30, n.3, p.675-680, 2008. Disponível em: <http://www.scielo.br/pdf/rbf/ v30n3/19.pdf>. Acesso em: 18 nov. 2013. doi: 10.1590/S010029452008000300019.
SILVA, L.C. et al. Raleio de cachos em vinhedos de altitude e qualidade do vinho da cultivar 'Syrah'. Pesquira Agropecuária Brasileira, Brasília, v.44, n.2, p.148-154, 2009. Disponível em: $<$ http://www.scielo.br/pdf/pab/v44n2/v44n02a06.pdf $>$. Acesso em: 18 nov. 2013. doi: 10.1590/S0100-204X2009000200006.

SINGLETON, V.L.; ROSSI, J.A. Colorimetry of total phenolics with phosphomolybdic - phosphotunestic acids reagents. American Journal of Enology and Viticulture, Davis, n.16, p. 144-158, 1965. Disponível em: <http://ajevonline.org/ content/16/3/144.full.pdf $>$. Acesso em: 18 nov. 2013.

TONIETTO, J.; CARBONNEAU, A. A multicriteria climatic classification system for grape-growing regions worlwide. Agricultural and Forest Meteorology, Amsterdam, v.124, p.8197, 2004. Disponível em: <http://www.sciencedirect.com/science/ article/pii/S0168192304000115>. Acesso em: 18 nov. 2013. doi: 10.1016/j.agrformet.2003.06.001.

ZALAMENA, J. Estado nutricional, vigor e produção em videiras cultivadas com plantas de cobertura. Revista Brasileira de Fruticultura, Jaboticabal, v.35, n.4, p.1190-1200, 2013. Disponível em: <http://ref.scielo.org/46s8sk>. Acesso em: 19 maio 2014. doi: 10.1590/S0100-29452013000400030. 